\title{
Low Flammability Plants Of The Cerrado For Green Fire Break
}

\author{
Michel Aquino de Souza.
}

${ }^{1}$ CBM-DF, Brasília, Brasil. E-mail: michel.pcif@ gmail.com.

\begin{abstract}
Low flammability plants in green fires break can protect against forest fires as they make it difficult to spread fire. Green firebreaks should be strategically implemented in plans for the recovery of fire degraded areas, stoped the flame and services a refuge. Compared to black and traditional firebreaks, green barriers can reduce erosion, vegetation diseases and population. It should be implanted in risk areas and on the threatened edges of the most vulnerable ecosystems especially in the wild interface urban. For vegetation, flammability is the time required for the start of the flames, considering continuity, speed and percentage of burning. The initial temperature of the highest mass loss is the spontaneous ignition temperature. This is the rate of mass loss in the gas phase of combustion and is directly proportional to the flammability and spread of the fire. The objective of this work was to characterize the thermal behavior of low flammability cerrado plants in the Federal District. The survey was based on the search for relatively preserved plants adjacent to the vegetation consumed by intense fire in the typical cerrado. In August 2014, we collected the leaves of Vochysia thyrsoidea, Palicourea rigida and Lavoisiera bergii greens and Echinolaena inflexa, as a control, for it is a highly flammable grass. Combustion tests were performed with flame initiation application and tests of Thermogravimetric Analysis (ATG). Data were analyzed by analysis of variance in a completely randomized design. $P$. rigida shows the flame start time of $143 \mathrm{~s}$ and the flame duration of $72 \mathrm{~s}$ in combustion experiment and spontaneous ignition temperature (TIE) of $245^{\circ} \mathrm{C}$ in the ATG test. V. thyrsoidea presented flames after $117 \mathrm{~s}$ with $89 \mathrm{~s}$ duration and TIE of $236^{\circ} \mathrm{C}$, and $L$. bergi-flame in $183 \mathrm{~s}$, duration $17 \mathrm{~s}$ and TIE of $246^{\circ}$ C. E. inflexa exhibited flames in the 70s, lasting $176 \mathrm{~s}$ and TIE $261^{\circ} \mathrm{C}$, significantly different from the others, with the highest combustion rate $(2.1 \mathrm{mg} / \mathrm{min})$. This way, corroborating the previous results, Vochysia thyrsoidea, Palicourea rigida and Lavoisiera bergii described as low flammability species with results that separate in $67 \%$ of the control species and are therefore indicated for use in green barriers.
\end{abstract}

Keywords: Palicourea, Vochysia, Echinolaena, Lavoisiera, ignition, thermometry. 